\title{
Mecanismos de defesa do trigo contra a ferrugem da folha por genes e proteínas
}

\author{
Geísa Finger $^{1}$, Leise Inês Heckler ${ }^{1}$, Gerarda Beatriz Pinto da Silva ${ }^{1}$, Márcia Soares Chaves ${ }^{2}$, José Antônio Martinelli ${ }^{1}$
}

${ }^{1}$ Departamento de Fitossanidade, Universidade Federal do Rio Grande do Sul, RS 91540-000. ${ }^{2}$ Embrapa Clima Temperado $96160-000$

Autor para correspondência: Geísa Finger (ge_finger@yahoo.com.br)

Data de chegada: 27/07/2016. Aceito para publicação em: : 06/03/2017.

$10.1590 / 0100-5405 / 167114$

\section{RESUMO}

Finger, G.; Heckler, L.I.; Silva, G.B.P.; Chaves, M.S.; Martinelli, J.A. Mecanismos de defesa do trigo contra a ferrugem da folha por genes e proteínas. Summa Phytopathologica, v.43, n.4, p.354-358, 2017.

O agente causal da ferrugem da folha do trigo é o fungo Puccinia triticina. Essa doença causa danos elevados que podem comprometer a produtividade da cultura do trigo em até $80 \%$, quando a infecção é intensa antes do florescimento e do enchimento de grãos. A utilização de cultivares resistentes é a melhor estratégia de controle da ferrugem da folha. Porém, devido à variabilidade do patógeno, a resistência dos genótipos é superada em até três anos após o seu lançamento. Para se defender da infecção do patógeno a planta desencadeia mecanismos de defesa, os quais têm a finalidade de evitar que o fungo colonize os tecidos do hospedeiro. Esses mecanismos de defesa podem estar associados com a expressão de genes que possuem a função de codificar proteínas envolvidas na resistência. Esta revisão discute a importância da interação plantapatógeno bem como das proteínas envolvidas. Também apresenta as principais técnicas de proteômica que visam identificar e quantificar as diferentes proteínas expressas nas células vegetais.

Palavras-chave: Triticum aestivum, Puccinia triticina, proteômica, resistência, infecção.

\section{ABSTRACT}

Finger, G.; Heckler, L.I.; Silva, G.B.P.; Chaves, M.S.; Martinelli, J.A. Wheat defense mechanisms by genes and proteins against leaf rust. Summa Phytopathologica, v.43, n.4, p.354-358, 2017.

The fungus Puccinia triticina is the causal agent of wheat leaf rust. This disease causes great damages, which may compromise wheat crop yields by up to $80 \%$ when the infection is intense before flowering and grain filling. The use of resistant cultivars is the best strategy to control leaf rust. However, due to the pathogen variability, genotype resistance is easily overcome within three years under field conditions. To defend against the pathogen infection, the plant triggers defense mechanisms, which aim to prevent the fungus from colonizing the host tissues. Such defense mechanisms may be associated with the expression of genes that have a role in encoding proteins involved in resistance. In this review, the importance of both the plant-pathogen interaction and the role of involved proteins is discussed. The main proteomic techniques to identify and quantify the different proteins expressed in plant cells are also presented.

Keywords: Triticum aestivum, Puccinia triticina, proteomics, resistance, infection.

A cultura do trigo (Triticum aestivum L.) possui grande importância no setor econômico mundial. Dentre os cereais mais produzidos no mundo, ocupa a terceira posição, superado apenas pelo milho e o arroz. Considerado a segunda cultura cerealífera, o trigo tem grande importância para a alimentação humana e está entre as primeiras culturas domesticadas (26). O grão de trigo é rico em nutrientes essenciais para o homem, possuindo em torno de 60 a $80 \%$ de carboidratos, vitaminas B e E, e proteínas (3). Cerca de $30 \%$ da população mundial encontra no cereal, e em seus derivados, a fonte primária de energia para sua dieta (15).

Os principais países produtores de trigo são China, União Européia, Estados Unidos, Índia, Rússia, Canadá e Argentina. A estimativa para 2018/2019 sugere que a produção brasileira de trigo chegue a 7,89 milhões de toneladas, sendo que o consumo é estimado em 12,25 milhões de toneladas, ou seja, a demanda pelo grão ainda é muito maior do que a produção interna de trigo no Brasil (10). Segundo dados da Conab (17), nos últimos anos a quantidade de trigo produzida no Brasil tem oscilado entre 5,0 e 6,0 milhões de toneladas, quantidade estimada para abastecer apenas $50 \%$ da demanda nacional. Para suprir essa demanda, o Brasil importa trigo principalmente da Argentina. No ano de 2015 houve uma redução na área cultivada com trigo de 10,8\%, porém, a produção estimada em 7,01 milhões toneladas foi superior à safra do ano anterior, devido à recuperação da produtividade no Rio Grande do Sul, a qual sofreu danos devido às condições ambientais adversas (18). As principais regiões produtoras de trigo no Brasil são: Sul, Sudeste e Centro-Oeste. Nesse quadro, o principal Estado produtor, o Paraná se destaca na produção nacional.

O genoma do trigo com tamanho de $17 \mathrm{~Gb}$, provém de Triticum urartu (doador do genoma A), Aegilops speltoides (doador do genoma B) e A. tauschii (doador do genoma D) sendo, portanto, uma espécie hexaploide $(2 \mathrm{n}=6 \mathrm{x}=42)$, AABBDD (47). Isso poderia explicar a capacidade que plantas de trigo possuem em se adaptar a várias condições ambientais (11).

Um dos principais problemas que compromete a produtividade da cultura do trigo são as doenças, em especial as ferrugens causadas pelos fungos do gênero Puccinia como a ferrugem da folha causada por $P$. triticina, a amarela por $P$. striiformis e a do colmo por $P$. graminis f.sp. tritici. No Brasil, a principal, que ocorre com maior frequência e causa mais danos é a ferrugem da folha.

Puccinia triticina Eriks., conhecida anteriormente como $P$. 
recondita f. sp. triticina Eriks. é o agente causal da ferrugem da folha do trigo. Uma doença altamente destrutiva que afeta a cultura mundialmente (15). O patógeno pertence a classe Pucciniomycetes, ordem Pucciniales, família Pucciniaceae, gênero Puccinia (7). Parasita obrigatório, requer o hospedeiro vivo para desenvolver seu ciclo de vida. É biotrófico, devido ao mecanismo que utiliza para retirar os nutrientes de células vivas do hospedeiro (48). No Brasil, a ferrugem da folha do trigo não possui hospedeiro alternativo e, portanto, não completa a sua fase sexual, ou seja, é uma doença autoécia, desenvolvendo-se em apenas um hospedeiro durante o seu ciclo de vida (42). O patógeno ataca todos os órgãos verdes, principalmente as folhas das plantas suscetíveis de trigo, embora possa infectar a bainha foliar e as glumas, provocando graves danos de produção em todas as regiões produtoras de trigo no mundo.

O processo de infecção e desenvolvimento da $P$. triticina tem início quando uredósporos dicarióticos são transportados principalmente pelo vento ou pelos respingos de chuva e depositados na face abaxial e adaxial das folhas de trigo. Essas estruturas ao entrarem em contato com um filme d'água na superfície foliar, absorvem água, incham e emitem o tubo germinativo para posterior evento de penetração. A temperatura ideal para os uredósporos germinarem e iniciarem o processo de infecção é de $20^{\circ} \mathrm{C}(34,42)$. Contudo, na ausência de água, os esporos podem sobreviver de 1 a 3 dias até que ocorra formação da lâmina d'água na superfície foliar $(2,7)$. O tubo germinativo cresce sobre a superfície da folha até que as reservas endógenas do esporo se esgotem ou que um estômato seja encontrado (21). Segundo Niks \& Dekens (49), quanto maior a energia gasta pelo patógeno no crescimento do tubo germinativo, menores são as chances de formação do haustório e de colonizar o tecido do hospedeiro. Os tubos germinativos que não encontram estômatos perdem a viabilidade.

Outra característica observada nos tubos germinativos de Puccinia spp. é o fato de possuírem a capacidade de perceber os sinais físicos impostos pela superfície foliar (1), como o espaçamento e posição das células localizadas perto dos estômatos e as características topográficas dos estômatos, formando sobre os mesmos um apressório. Cerca de 6 $\mathrm{h}$ após a inoculação de $P$. triticina em folhas de trigo, o fungo penetra na câmara subestomática e forma uma vesícula substomatal e uma hifa infectiva (34). Ao entrarem em contato com a parede celular de células do mesófilo, as hifas infectivas se diferenciam em célulasmãe-de-haustório. Isso ocorre cerca de $12 \mathrm{~h}$ após a inoculação e, após 24 h, no espaço periplasmático, uma célula especializada se expande formando o haustório. Na interação compatível, cerca de cinco dias após a infecção, origina-se um tecido esporogênico abaixo da epiderme que iniciará a formação dos esporos (29). Após 07-10 dias os esporos rompem a cutícula formando as pústulas e a massa de uredósporos localizada no centro das frutificações confere às pústulas uma coloração laranja-amarelada (30). Dessa forma, as pústulas podem afetar uma grande área fotossintetizante da folha, diminuindo as trocas gasosas, translocação de produtos da fotossíntese das folhas para o grão em formação, reduzindo o valor comercial e nutricional do grão (62).

Para compreender os efetores produzidos por haustórios que, tem a função de interagir com o hospedeiro e "driblar" seus mecanismos de defesa através da síntese principalmente de proteínas além de, desempenhar um papel importante na virulência com plantas de trigo $(40 ; 38)$, as proteínas produzidas por $P$. triticina (isolado 90-1, raça-1, código $\mathrm{BBBD}$ ) foram purificadas próximo à homogeneidade através de imunoprecipitação com anticorpos monoclonais preparados especificamente para haustórios deste fungo. Foram identificadas 1192 proteínas de haustório dentre as quais 140 foram candidatas a proteínas efetoras baseado na presença de um peptídeo sinalizador e ausência de uma função conhecida para a proteína (54).

\section{Principais genes e seus mecanismos de resistência em cereais de inverno}

A capacidade do hospedeiro em impedir o crescimento e o desenvolvimento do patógeno é denominada resistência genética (52). Essa resistência pode assumir várias classificações. Uma delas é a resistência de não-hospedeiro ou imunidade, mecanismo esse que as plantas possuem à maioria dos patógenos. Do ponto de vista evolutivo são conservados e incluem principalmente mecanismos estruturais e bioquímicos. Um outro tipo é a resistência de hospedeiro, onde o patógeno consegue infectar a planta de uma espécie hospedeira, porém a severidade da doença varia na planta infectada. Essa variação pode ser quali- ou quantitativa. A resistência qualitativa também é conhecida como resistência do "tudo ou nada" ou seja, a planta é resistente ou suscetível frente ao patógeno. Os genes envolvidos nesse tipo de resistência geralmente codificam proteínas pertencente à família com sítios de ligação a nucleotídeos ricos em leucina (NBS-LRR) (44).

$\mathrm{Na}$ resistência quantitativa ou parcial há uma variação no grau de resistência, indo de plantas altamente resistentes até altamente suscetíveis (13). O gene de resistência Yr36 que confere resistência à ferrugem amarela do trigo codifica uma proteína com um domínio quinase ligado a um domínio lipídico (27). O gene recessivo pi26 que confere resistência a brusone do arroz codifica uma proteína rica em prolina (28) e o gene recessivo mlo que confere resistência a oídio em cevada codifica uma proteína integral da membrana plasmática (12). Genes de resistência quantitativa ou parcial geralmente são mais duráveis quando comparados com genes R e podem conferir resistência raça não específica (43). Além disso, as proteínas envolvidas com essa resistência são codificadas por esses genes e são heterogêneas (23).

Estudos da variabilidade genética desde 1979 até 2010 determinaram 59 raças de $P$. triticina a partir da diferenciação pela expressão de cada gene de resistência $L r$, ou seja, em média uma a três raças novas por ano (6). A compreensão da herança da resistência a doenças é importante para o planejamento de cruzamentos em programas de melhoramento, na identificação de genes de resistência e no desenvolvimento de marcadores genéticos para a seleção assistida. Visto isso, Brammer et al., (9) através da obtenção de progênies duplo haplóide, realizaram análises genéticas da resistência de planta adulta em trigo contra $P$. triticina, com o objetivo de estudar os padrões de herança e o número de genes envolvidos na resistência durável de planta adulta na cultivar de trigo BR 35. Para isso, a cultivar BR 35, a qual possui resistência à ferrugem da folha há mais de 12 anos, mesmo sob alta pressão de inóculo na região sul do Brasil, e a cultivar IAC 13-Lorena, que é suscetível, foram cruzadas para produzir uma população segregante a fim de detalhar a resistência de BR 35. Após a população ter sido desafiada com as raças MCG e LPG de P. triticina, os autores concluíram que BR 35 possui dois genes de resistência, sendo que apenas um é expresso após o estádio intermediário do desenvolvimento da planta (5-6 folhas).

Segundo Parlevliet (52), a resistência em cereais à ferrugem pode ser classificada em três tipos: resistência de plântula, resistência de planta adulta e resistência parcial. Os genes envolvidos na resistência de planta adulta (RPA) são efetivos apenas no estádio de planta adulta. Essa resistência é caracterizada por genes de resistência de efeito menor e é dita de natureza parcial, a qual permite o desenvolvimento da doença, mas sem causar redução econômica ao rendimento da cultura (61). Um exemplo é o gene $L r 34$, o qual codifica uma proteína transmembrana, pertencente à família de transportadores $\mathrm{ABC}$, que utiliza a hidrólise do ATP para transportar vários substratos através da membrana celular (55). 
Estudos histológicos realizados entre Puccinia x Poaceae demonstraram dois principais mecanismos de resistência, pré e póshaustoriais. Geralmente, após o uredósporo formar o apressório e a vesícula substomatal, os genótipos envolvidos na interação Puccinia $\mathrm{x}$ hospedeiro irão diferenciar seus mecanismos em pré ou pós-haustorial $(32,62)$. Na resistência pré-haustorial geralmente ocorre a indução de papila no local de penetração das células-mãe-de-haustório, impedindo o crescimento do fungo sem causar necrose celular. Interações entre patógeno e plantas não-hospedeiras comumente possuem esse tipo de resistência, porém a mesma pode ocorrer em interações entre o patógeno e plantas hospedeiras, como em linhagens com resistência parcial à ferrugem da folha da cevada (57).

O gene mlo em cevada é um exemplo de resistência pré-haustorial durável, pois confere resistência a praticamente todas as raças do agente causal do oídio Blumeria graminis f. sp. hordei. Além disso, está envolvido na formação de papila no local de penetração do patógeno e ocorrência de reação de hipersensibilidade (HR), a qual é uma exceção nos casos em que mecanismos pré-haustoriais estão envolvidos (50, 62). Acredita-se que a resistência pré-haustorial seja mais durável em interações patógeno $\mathrm{x}$ hospedeiro, pois vários mecanismos de defesa do hospedeiro estão envolvidos nesse tipo de resistência, os quais colaboram efetivamente para que não ocorra a colonização por parte do patógeno $(50,31)$.

Genes de efeito maior (raça-específica) com mecanismos póshaustoriais são na sua maioria os principais genes envolvidos na resistência contra as ferrugens. A resistência pós-haustorial, a qual paralisa o crescimento do fungo após a formação de pelo menos um haustório, desencadeia a HR, que causa a morte da célula ou células em que o haustório está localizado (50). Segundo trabalho histopatológico com plantas de trigo contendo os genes $\operatorname{Lr} 12$ e $L r 13$, os quais conferem resistência de planta adulta à ferrugem da folha, Bender et al., (5) inferiram que os mesmos possuem mecanismos de resistência préhaustorial, reduzindo a penetração de apressórios e abortamento de vesículas subestomatais.

A utilização de cultivares de trigo resistentes à ferrugem da folha é a forma mais eficiente e econômica de controlar a doença. Porém, devido a variabilidade do patógeno, o qual pode se diferenciar em uma ou três novas raças/ano, essa resistência é facilmente superada. A superação da efetividade da resistência está levando os pesquisadores à busca de cultivares de trigo com formas de resistência mais durável (35). O mercado brasileiro atual possui cultivares de trigo com genes de resistência de planta adulta. Genes $L r 35, L r 37$ e $L r 22 a$ conferem resistência de planta adulta, porém, são específicos a raças. Já os genes Lr34 e Lr46 são genes de resistência de planta adulta não específicos a raças. O CIMMYT fornece materiais que possuem genes que conferem resistência de planta adulta, e são utilizados em cruzamentos com linhagens adaptadas em programas de melhoramento na América do Sul assim como Parula ( $L r 34, L r 46+$ um ou dois genes menores), Chapio ( $L r 34+$ três ou quatro genes menores), Amadina (quatro genes menores) entre outras linhagens com esse tipo de resistência (4).

A cultivar de trigo Toropi (Petiblanco 8//Frontana 1971-37/ Quaderna A), é descendente da cultivar Frontana, que possui RPA durável à ferrugem da folha e ainda hoje serve como fonte de resistência para outras cultivares. Análises genéticas do Centro Internacional de Melhoramento de Milho e Trigo (CIMMYT) sobre a cultivar Frontana demonstrou que a RPAé baseada no complexo $\operatorname{Lr} 34$ que envolve o gene Lr34 (58), assim como Lr13 mais um modificador ou modificadores, $L r 34$ e $L r T 3$ além de outros genes $(22,56)$.

Os genes denominados $\operatorname{Lr}$ (leaf rust) conferem resistência à ferrugem da folha em trigo. A espécie diplóide Aegilops speltoides, é doadora do genoma $\mathrm{B}$ à espécie T. aestivum e se destaca como uma importante fonte de genes de resistência à ferrugem (46). Cultivares que possuem RPA e genes de pequeno efeito ou intermediários, porém aditivos, demonstram possuir resistência à ferrugem por mais tempo (35). Essas plantas são suscetíveis no estádio de plântula, pois os genes de RPA são expressos à medida que a planta se desenvolve.

A cultivar Toropi, lançada no mercado em 1965, possui resistência de planta adulta à ferrugem da folha. Apesar de transcorridos mais de 50 anos desde o seu lançamento, essa cultivar ainda apresenta resistência à doença, a qual é conferida principalmente por dois genes recessivos designados temporariamente de $\operatorname{Tr} p-1$ e Trp-2 localizados nos cromossomos $1 \mathrm{AS}$ e 4DS, respectivamente $(8,19)$. Além disso, a cultivar possui tolerância ao alumínio, além de absorção, translocação e distribuição de fósforos aumentadas (24), bem como resistência à fusariose $(41,14)$.

Wesp-Guterres (62) avaliou os processos infectivos envolvidos na interação entre Toropi e $P$. triticina. A cultivar apresentou redução na formação de vesículas subestomatais e de todos os eventos infectivos posteriores à formação dessa estrutura, comparado com a testemunha suscetível BRS 194. Além disso, 5 dias após a inoculação 37\% das tentativas de infecção estiveram associadas com a morte celular, evento que não ocorre com os genes $L r 34$ e $L r 46$. Isso porque, estes, apesar de restringirem o processo infectivo do patógeno nas fases iniciais, não induzem a morte celular. Portanto, a resistência de Toropi parece envolver mecanismos pré e pós-haustoriais.

Casassola et al., (14) avaliaram a expressão de 15 genes relacionados com o processo de defesa em trigo na cv. Toropi. Os genes de proteína precursora de transferência de lipídeo não-especifica tipo I (LTP), os de proteína precursora de ligação à clorofila a/b (WCAB), os de aquaporinas (AQP1), os de peroxidase de raiz (PRA2), proteínas relacionadas à patogênese (PR-2 e PR-9) tiveram pico de expressão anterior a 24 hai e parecem estar envolvidos na resistência pré-hautorial da cultivar. Já os genes de ácido cafeico O-metiltransferase (COMT1), proteínas relacionadas à patogênese (PR-1 e $\mathrm{PR}-4)$ apresentaram pico de expressão posterior a 24 hai e parecem estar envolvidos na resistência pós-haustorial.

\section{A proteômica em auxílio à compreensão da interação planta- patógeno}

O maior desafio atualmente é entender a síntese das proteínas, o mais complexo dos processos biossintetizantes. Em eucariotos quase 300 macromoléculas diferentes estão envolvidas na síntese de proteínas (45). Portanto, dentro da ciência das "ômicas", a proteômica é a principal ferramenta de estudo da síntese de proteínas.

O termo proteoma foi cunhado pelo Dr. Marc Wilkins da Universidade de Macquarie, na Austrália, em 1994. Pode ser compreendido como o conjunto total de proteínas de uma espécie ou produto gênico presente em uma unidade biológica (ecossistema, população, organismo, órgão, tecido, célula ou organela), em um determinado estádio de desenvolvimento e sobre determinada condição biótica e abiótica externa (37).

Avaliações da expressão gênica em níveis de transcriptoma são importantes. Porém, as informações obtidas pela análise de transcriptoma podem ser incompletas pelo fato de ocorrerem muitas modificações pós-traducionais, assim como interações entre as proteínas. Portanto, a correlação entre mRNA e níveis de proteínas é baixa (36). A proteômica encarrega-se do estudo sistemático de um proteoma e permite avaliações quantitativas e qualitativas de proteínas que atuam no metabolismo celular $(51,16)$.

Atualmente, os estudos em proteômica estão mais desenvolvidos 
nas áreas humanas, quando comparada às espécies vegetais. Dentre as espécies de estudo estão Arabidopsis, arroz e trigo (20). Técnicas modernas em proteômica permitem o estudo de diferentes concentrações de proteínas dentro das células, as quais podem ser sintetizadas diferencialmente em células submetidas a diferentes condições fisiológicas e relacionadas com estresse. Por exemplo, quando ocorre interação entre planta e patógeno, a mesma pode causar mudanças na síntese de proteínas nas células da planta em resposta ao estresse gerado (25). A técnica mais utilizada para o fracionamento proteico é a eletroforese bidimensional (2-DE). Desenvolvida em 1970, é um processo trabalhoso e demorado. Contudo, é a principal estratégia de análise proteômica em plantas, a qual tem por objetivo a separação e seleção das proteínas no gel 2-DE, posterior identificação das proteínas por espectrometria de massa e cruzamento com os bancos de dados disponíveis (60). Tecidos vegetais são compostos por células as quais são constituídas por parede celular e vacúolos que possuem moléculas como ácidos orgânicos, carboidratos, lipídios e fenóis. Portanto, a etapa de extração requer maior atenção, visto que essas moléculas podem interferir na análise proteômica (33).

A eletroforese 2-D é um método amplamente utilizado para análise de misturas complexas de proteínas, as quais podem ser extraídas a partir de células, tecidos ou de outras amostras biológicas. Essa técnica separa as proteínas de acordo com duas propriedades independentes. A primeira está baseada na separação das proteínas de acordo com o seu ponto isoelétrico (pi) e, a segunda, está baseada na eletroforese de gel dodecil sulfato de sódio-poliacrilamida (SDS-PAGE), a qual separa as proteínas de acordo com seu peso molecular. Cada ponto no gel bidimensional corresponde potencialmente a uma única proteína na amostra. Portanto, milhares de proteínas diferentes podem ser separadas de acordo com o pi da proteína e peso molecular aparente, sendo possível também obter-se a quantidade de cada proteína.

Atualmente, os avanços na espectrometria de massa (MS) permitiram uma revolução na bioquímica, pois pode ser utilizado para identificar uma única proteína ou milhares de proteínas presentes em uma mistura complexa com relativa facilidade. A espectrometria de massa MALDI-TOF (Matrix Assisted Laser Desorption Ionization Time-of-Flight) tornou-se uma das mais importantes técnicas para a identificação de proteínas e peptídeos. É importante no estudo da proteômica pois desempenha papel fundamental na identificação de potenciais proteínas alvo. Segundo Sparkman (59) a espectrometria de massa é uma técnica analítica que identifica a composição química de um composto ou amostra. As moléculas ionizadas ganham ou perdem suas cargas por protonação, desprotonação ou ejeção de elétrons. São eletrostaticamente impulsionadas para dentro do aparelho e detectadas de acordo com sua massa por relação de carga (53). De cordo com KANG et al.; (39), quando plântulas de trigo foram tratadas com 0,5 $\mathrm{mM}$ de ácido salicílico (AS), $250 \mathrm{mM} \mathrm{NaCl}$ e $250 \mathrm{mM} \mathrm{NaCl}+0,5 \mathrm{mM}$ AS para avaliar a influência do AS nos mecanismos de tolerância ao sal em trigo e um total de 39 proteínas diferencialmente reguladas para ambos sal e AS foram reveladas por 2D PAGE e 38 proteínas foram identificadas por MALDI-TOF/TOF MS. As proteínas identificadas estavam envolvidas em várias respostas celulares e processos metabólicos incluindo tradução de sinais, estresse de defesa, energia, metabolismo, fotossíntese e outras funções desconhecidas.

Portanto, estratégias que auxiliem o desenvolvimento de cultivares resistentes têm sido o foco de muitos estudos atualmente. Cultivares de trigo resistentes às principais doenças que ocorrem na cultura são uma forma de diminuir o uso de fungicidas e amenizar os danos causados no meio ambiente. Cultivares mais antigas, como Toropi, as quais conferem resistência parcial à ferrugem da folha, podem ser utilizadas como possíveis doadoras de genes. Para tanto, estudos de genômica, transcriptoma e proteômica são fundamentais para estabelecer as relações existentes entre a interação planta-patógeno e consequentemente utilizá-las para o melhoramento de plantas de trigo.

\section{REFERÊNCIAS}

1. Allen, E.A.; Hazen, B.E.; Hoch, H.C.; Kwon, Y.; Leinhos, G.M.E.; Staples, R.C.; Stumpf, M.A.; Terhune, B.T. Appressorium formation in response to topographical signals in 27 rust species. Phytopathology, Saint Paul, v.81, p.323-331, 1991

2. Allen, R.F. A cytological study of Puccinia triticina physiologic form II on Little Club wheat. Journal of Agricultural Research, Washington, v.33, p.201-222, 1926.

3. Barbieri, R.L.; Stumpf, E.R.T. Origem e evolução de plantas cultivadas. Brasília, DF: Embrapa, 2008. 909p.

4. Bender, C.M.; Pretorius, Z.A.; Kloppers, F.J.; Spies, J.J. Histopathology of leaf rust infection and development in wheat genotypes containing $\operatorname{Lr} 12$ and Lr13. Journal of Phytopathology, Berlin, v.148, p.65-76, 2000.

5. Bianchin, V.; Barcellos, A.L.; Reis, E.M.; Turra, C. Genetic variability of Puccinia triticina Eriks. in Brazil. Summa Phytopathologica, Botucatu, v.38, n.2, p.113-118, 2012.

6. Bolton, D.M.; Kolmer, A.J.; Garvin, F.D. Wheat leaf rust caused by Puccinia triticina. Molecular Plant Pathology, Oxford, v.5, p.563-575, 2008.

7. Brammer, S.P. Mapeamento de genes de resistência parcial à ferrugem da folha em cultivares brasileiras de trigo (Triticum aestivum L. em Thell). 2000. 105f. Tese (Doutorado em Genética e Biologia Molecular) - Faculdade de Ciências Biológicas, Universidade Federal do Rio Grande do Sul, Porto Alegre.

8. Brammer, S.P.; Moraes-Fernandes, M.I.B.; Barcellos, A.L.; Milach, S.C.K. Genetic analysis of adult-plant resistance to leaf rust in a double haploid wheat (Triticum aestivum L. em Thell.) population. Genetics and Molecular Biology, Ribeirão Preto, v. 27, p. 432-436. 2004.

9. Brasil. Empresa Brasileira de Pesquisa Agropecuária. Brasil é capaz de produzir além de sua demanda doméstica de trigo. Brasília, 2016. Disponível em: <https://www.embrapa.br/busca-de-noticias/-/noticia/18671088/ brasil-e-capaz-de-produzir-alem-de-sua-demanda-domestica-de-trigo>. Acesso em: 12 dez. 2016.

10. Brenchley, R.; Spannagl, M.; Pfeifer, M.; Barker, G.L.; D'Amore, R.; Allen, A.M.; McKenzie, N.; Kramer, M.; Kerhornou, A.; Bolser, D.; Kay, S. Analysis of the bread wheat genome using whole-genome shotgun sequencing. Nature, London, n.491, p.705-710, 2012.

11. Büschges, R.; Hollricher, K.; Panstruga, R.; Simons, G.; Wolter, M.; FrijF ters, A.; van Daelen, R.; van der Lee, T.; Diergaarde, P.; Groenendijk, J.; Töpsch, S. The barley mlo gene: a novel control element of plant pathogen resistance. Cell, Amsterdam, v.88, p.695-705, 1997.

12. Camargo, L.E.A. Genética da interação patógeno-hospedeiro. In: Amorim, L.; Rezende, J.A.M.; Bergamin, F.A. Manual de fitopatologia: princípios e conceitos. 4.ed. Piracicaba: Agronômica Ceres, 2011. v.1, p.125.

13. Casassola, A.; Brammer, S.P.; Chaves, M.S.; Martinelli, J.A.; Stefanato, F.; Boyd, L.A. Changes in gene expression. Profiles as they relate to the adult plant leaf rust resistance in the wheat cv. Toropi. Physiological and Molecular Plant Pathology, London, v.89, p.49-54, 2015.

14. Chaves, M.S.; Martinelli, J.A.; Wesp-Guterres, C.; Graichen, F.A.S.; BramB mer, S.P.; Scagliusi, S.M.; da Silva, P.R.; Wiethölter, P.; Torres, G.A.M.; Lau, E.Y.; Consoli, L. The importance for food security of maintaining rust resistance in wheat. Food Security, Berlin, v.5, p.157-176, 2013.

15. Chen, S.X.; Harmon, A.C. Advances in plant proteomics. Proteomics, Weinheim, v.6, p.5504-5516, 2006.

16. Companhia Nacional de Abastecimento - Conab. Acompanhamento da safra brasileira de grãos: Safra 2014/15, Brasília, DF, v.2, n.10, p.1-109, 2015. Disponível em: <http://www.conab.gov.br/OlalaCMS/uploads/arquivos/16_01_12_09_00_46_boletim_graos_janeiro_2016.pdf>. Acesso em: 15 jan. 2016.

17. Companhia Nacional de Abastecimento - Conab. Acompanhamento da safra brasileira de grãos: Safra 2013/2014, Brasília, DF, v.1, n.7, p.1-86, 2014. Disponível em: <http://www.conab.gov.br/OlalaCMS/uploads/ arquivos/14_04_14_11_56_28_boletim_graos_abril_2014>. Acesso em: 
15 jan. 2016.

18. Da-Silva, P.R.; Brammer, S.P.; Guerra, D.; Milach, S.C.; Barcellos, A.L.; Baggio, M.I. Monosomic and molecular mapping of adult plant leaf rust resistance genes in the Brazilian wheat cultivar Toropi. Genetics and Molecular Research, Ribeirão Preto, v.11, n.3, p.2823-2834, 2012.

19. De Godoy, L.M.; Olsen, J.V.; de Souza, G.A.; Li, G.; Mortensen, P.; Mann, M. Status of complete proteome analysis by mass spectrometry: SILAC labeled yeast as a model system. Genome biology, London, v.7, n.6, p.1, 2006.

20. Dickinson, S. Studies in the physiology of obligate parasitism. Journal of Phytopathology, Berlin, v.66, p.38-49, 1969

21. Dyck, P.L.; Samborski, D.J.; Anderson, R.G. Inheritance of adult-plant leaf rust resistance derived from the common wheat varieties Exchange and Frontana. Canadian Journal of Genetics Cytology, Ottawa, v.8, p.665-671, 1966.

22. Ellis, J.G.; Lagudah, E.S.; Spielmeyer, W.; Dodds, P.N. The past, present and future of breeding rust resistant wheat. Frontiers in Plant Science, Lausanne, v.5, p.641, 2014.

23. Espindula, L.F.; Minella, E.; Delatorre, C.A. Low-P tolerance mechanisms and differential gene expression. Pesquisa Agropecuária Brasileira, Brasília, DF, v.44, n.9, p.1100-1105, 2009.

24. Fang, X.; Chen, J.; Dai, L.; Ma, H.; Zhang, H.; Yang, J.; Wang, F.; Yan, C. Proteomic dissection of plant responses to various pathogens. Proteomics, Weinheim, v.15, n.9, p.1525-1543, 2015.

25. Food and Agriculture Organization of the United Nations - FAO. Crop Prospects and Food Situation. Italy, march 2013. Disponível em: $<$ http:// www.fao.org/3/a-a1998e.pdf>. Acesso em: 20 jan. 2016.

26. Fu, D.; Uauy, C.; Distelfeld, A.; Blechl, A.; Epstein, L.; Chen, X.; Sela, H.; Fahima, T.; Dubcovsky, J. A kinase-START gene confers temperature-dependent resistance to wheat stripe rust. Science, Washington DC, v.323, p.1357-1360, 2009

27. Fukuoka, S.; Saka, N.; Koga, H.; Ono, K.; Shimizu, T.; Ebana, K.; Hayashi, N.; Takahashi, A.; Hirochika, H.; Okuno, K.; Yano, M. Loss of function of a proline-containing protein confers durable disease resistance in rice. Science, Washington DC, v.325, p.998-1001, 2009.

28. Harder, D.E. Electron microscopy of urediospore formation in Puccinia coronate f. sp. avenae. Canadian Journal of Botany, Ottawa, v.54, p.1010-1019, 1976.

29. Harder, D.E.; Haber, S. Genetics and inheritance in oat. In: Marshall, H.G.; Shaner, E.G. Oat science and technology. Madison: American Society of Agronomy, p. 125, 1992.

30. Heath, M.C. Nonhost resistance and nonspecific plant defenses. Current Opinion in Plant Biology, London, v.3, p.315-319, 2000.

31. Heath, M.C. Resistance of plants to rust infection. Phytopathology, Saint Paul, v.71, n.9, p.971-974, 1981

32. Hochholdinger, F.; Sauer, M.; Dembinsky, D.; Hoecker, N.; Muthreich, N.; Saleem, M.; Liu, Y. Proteomic dissection of plant development. Proteomics, Weinheim, v.6, p.4076-4083, 2006.

33. Hu, G.; Rijkenberg, F.H. Scanning electron microscopy of early infection structure formation by Puccinia recondita f. sp. tritici on and in susceptible and resistant wheat lines. Mycological Research, Cambrigde, v.102, p.391-399, 1998.

34. Huerta-Espino, J.; Singh, R.P.; German, S.; McCallum, B.D.; Park, R.F.; Chen, W.Q.; Bhardwaj, S.C.; Goyeau, H. Global status of wheat leaf rust caused by Puccinia triticina. Euphytica, Dordrecht, v.179, p.143-160, 2011.

35. Jorrín, J.V.; Rubiales, D.; Dumas-Gaudot, E.; Recorbet, G.; Maldonado, A.; Castillejo, M.A.; Curto, M. Proteomics: a promising approach to study biotic interaction in legumes: a review. Euphytica, Dordrecht, v.147, p.37-47, 2006.

36. Jorrín-Novo, J.V.; Pascual, J.; Sánchez-Lucas, R.; Romero-Rodríguez, M.C.; Rodríguez-Ortega, M.J.; Lenz, C.; Valledor, L. Fourteen years of plant proteomics reflected in Proteomics: moving from model species and 2DE-based approaches to orphan species and gel-free platforms. Proteomics, Weinheim, v.15, p.1089-1112, 2015.

37. Kamouns, S. The secretome of plant-associated fungi and oomycetes. In: Deising, H. (Ed.). The Mycota V. Berlin Heidelberg: Springer, p. 173$180,2009$.

38. Kang, G.; Li, G.; Zheng, B.; Han, Q.; Wang, C.; Zhu, Y.; Guo, T. Proteomic analysis on salicylic acid-induced salt tolerance in common wheat seedlings
(Triticum aestivum L.). Biochimica et Biophysica Acta (BBA)-Proteins and Proteomics, Weinheim, v.1824, n.12, p.1324-1333, 2012.

39. Koeck, M.;S, Hardham, R. A.; Dodds, N.P. The role of effectors of biotrophic and hemibiotrophic fungi in infection. Cellular Microbiology, v.13, n.12, p.1849-1857, 2011.

40. Kohli, M.M. Taller sobre la fusariosis de la espiga en America del Sur. Cidade do México: CIMMYT, 1989. 144p.

41. Kolmer, J. Leaf rust of wheat: pathogen biology, variation and host resistance. Forests, Basel, v.4, p.70-84, 2013

42. Kou, Y.; Wang, S. Broad-spectrum and durability: understanding of quantia tative disease resistance. Current opinion in plant biology, Lodon, v.13, p.181-185, 2010.

43. Krattinger, S.G.; Sucher, J.; Selter, L.L.; Chauhan, H.; Zhou, B.; Tang, M.; Upadhyaya, N.M.; Mieulet, D.; Guiderdoni, E.; Weidenbach, D.; Schaffrath, U. The wheat durable, multipathogen resistance gene Lr34 confers partial blast resistance in rice. Plant Biotechnology Journal, Oxford, v.14, p.1261-1268, 2016.

44. Lehninger, A.L.; Nelson, D.L.; Cox, M.M. Princípios de bioquímica. 2.ed. São Paulo: Sarvier, 2000. 839p.

45. Li, Z.; Lan, C.; He, Z.; Singh, R.P.; Rosewarne, G.M.; Chen, X.; Xia, X. Overview and application of QTL for adult plant resistance to leaf rust and powdery mildew in wheat. Crop Science, Madison, v.54, p.1907$1925,2014$.

46. Marcussen, T.; Sandve, S.R.; Heier, L.; Wulff, B.B.; Steuernagel, B.; Mayer, K.F.; Olsen, O.A. A chromosome-based draft sequence of the hexaploid bread wheat (Triticum aestivum) genome. Science, Washington DC, v.345, n.6194, p.1251788, 2014.

47. Mendgen, K.; Hahn, M. Plant Infection and the establishment of fungal biotrophy. Trends Plant Science, Oxford, v.7, p.352-356, 2002.

48. Niks, R.E. Effect of germ tube length on the fate of sporelings of Puccinia hordei in susceptible and resistance barley. Phytopathology, Saint Paul, v.80, p.57-60, 1990

49. Niks, R.E.; Dekens, R.G. Prehaustorial and posthaustorial resistance to wheat leaf rust in diploid wheat seedling. Phytopathology, Saint Paul, v.81, p.847-851, 1991.

50. Park, O.K. Proteomic studies in plants. Journal of Biochemistry and Molecular Biology, Berlin, v.37, p.133-138, 2004.

51. Parlevliet, J.E. Present concepts in breeding for disease resistance. Fitopatologia Brasileira, Lavras, v.22, p.7-15, 1997. Suplemento.

52. Quirino, B.F.; Candido, E.S.; Campos, P.F.; Franco, O.L.; Krüger, R.H. Proteomic approaches to study plant-pathogen interactions. Phytochemistry, New York, v.71, p.351-362, 2010.

53. Rampitsch, C.; Günel, A.; Beimcik, E.; Mauthe, W. Proteome of monoclonal antibody-purified haustoria from Puccinia triticina Race-1. Proteomics, Weinheim, v.15, n.7, p.1307-15, 2015.

54. Rea, P.A. Plant ATP-binding cassette transporters. Annual Review of Plant Biology, Palo Alto, v.58, p.347-375, 2007.

55. Roelfs, A.P. Resistance to leaf rust and stem rust in wheat. In: Rajaram, S.; Singh, R.P.; Torres, E. Breeding strategies for resistance to the rust of wheat. México: CIMMYT, 1988. p.10-22.

56. Rubiales, D.; Moral, A. Prehaustorial resistance against alfalfa rust (Uromyces striatus) in Medicago truncatula. European Journal of Plant Pathology, Dordrecht, v.110, p.239-243, 2004.

57. Singh, R. P. Association between gene Lr34 for leaf rust resistance and leaf tip necrosis in wheat. Crop Science, Madison, v.32, p.874-878, 1992.

58. Sparkman, O.D. Mass spectrometry desk reference. Global View Publications, Pittsburgh, 2000

59. Takác, T.; Pechan, T.; Richter, H.; Müller, J.; Eck, C.; Böhm, N.; Obert, B.; Ren, H.; Niehaus, K.; Samaj, J. Proteomics on brefeldin A-treated Arabidopsis roots reveals profilin 2 as a new protein involved in the crosstalk between vesicular trafficking and the actin cytoskeleton. Journal of Proteome Research, Washington, v.10, p.488-501, 2011.

60. Vale, F.X.R.; Parlevliet, J.E.; Zambolim, L. Concepts in plant disease resise tance. Fitopatologia Brasileira, Brasília, DF, v.26, n.3, p.577-589, 2001.

61. Wesp-Guterres, C.; Martinelli, J.A.; Graichen, F.A.S.; Chaves, M.S Histopathology of durable adult plant resistance tom leaf rust in the Brazilian wheat variety Toropi. European Journal of Plant Pathology, Dordrecht, v.137, n.1, p.181-196, 2013. 